\title{
Reflections on the Reform of Medical Education in Contemporary Colleges and Universities
}

Yu Song, Hongbo Chu, Zhongwei Zhao, Mingxing Wang

Changchun University, Changchun 130022, Jilin, China.

Abstract: The advancement of science and technology and the advent of a new era have made my country's medical education field show more vigorous vitality in the continuous development of the times. Therefore, how to improve the medical education reform in colleges and universities under the current social background has become a problem that needs to be solved by people. From different angles, the author looks for specific ways to promote reforms in an orderly manner, hoping to provide references for other medical educators.

Keywords: Educational Reform; Educational Thinking; Higher Education; Medical Classroom

Outdated teaching concepts severely constrain the orderly development of medical education. Many teachers focus their teaching on imparting professional knowledge to students, but seldom educate students on how to apply knowledge, resulting in a serious reduction in students' practical ability and professional literacy. In addition, the medical professional courses are not only large in content, but also very rigorous. Many students often use mechanical memory to learn in order to ensure exam results. This will not only seriously reduce its learning initiative, but also seriously reduce its learning efficiency. This requires teachers to keep up with the development of the times and actively find specific ways to promote the orderly development of education reform. In order to mobilize students' enthusiasm for learning, they can ensure professionalism in the highly effective medical classrooms established by teachers. The grasp of theoretical knowledge can also train their professional skills and practical skills at the same time, and then grow into high-quality medical talents that meet the needs of the country.

\section{Give full play to students' subjectivity, construct heuristic teaching classroom}

If medical education reform is to proceed smoothly, teachers in colleges and universities should break through the constraints of outdated teaching concepts when conducting teaching work. When carrying out medical classrooms, they cannot blindly use themselves as teaching centers and actively explain knowledge to students. In such a classroom that places too much emphasis on the teacher's own teaching subjectivity, not only can students not exert their own subjective initiative in learning, but also develop bad habits of relying on teachers for knowledge learning under the long-term teacher's teaching method, thereby seriously inhibiting their own learning Enhancing enthusiasm and thinking ability. Therefore, teachers need to be aware of the positive significance of developing students' subjectivity in the emerging education perspective. Although teachers' explanation of knowledge can help students quickly grasp medical concepts, they can't ignore the guidance of students' divergent thinking in order to make students full In the process of mobilizing the enthusiasm of participating in medical knowledge, to ensure the smooth progress of teaching work.

Therefore, when carrying out medical education reform, teachers should start with the knowledge reserves, speculation and learning needs of class students, and design the classroom teaching plan in accordance with the interests and hobbies of college students to find inspiration that can guide students to actively think about knowledge. Classroom. This will not only enable

Copyright(C) 2020 Yu Song et al.

doi: 10.18686/ahe.v4i10.2912

This is an open-access article distributed under the terms of the Creative Commons Attribution Non-Commercial License (http://creativecommons. org/licenses/by-nc/4.0/), which permits unrestricted non-commercial use, distribution, and reproduction in any medium, provided the original work is properly cited. 
students to quickly grasp the knowledge during active inquiry, but also enable students to get rid of the bad habits of relying on teachers for learning, and ensure the rapid rise of learning efficiency through the spread of their own speculative consciousness.

\section{Extend the content of the lecture to arouse students' memory enthusiasm}

In order to enable students to achieve high-quality test scores during the teaching work, many teachers often give priority to the content of the classroom knowledge and rarely extend the corresponding content. This not only prevents the students from learning the knowledge that can be combined with the continuous introduction of new medical content. In order to ensure the test scores, the students can only learn the medical knowledge by rote, which will affect the students' enthusiasm for learning. This requires teachers to actively use the Internet to collect some of the latest medical knowledge and introduce it into the teaching content before starting the medical classroom, so that students can not only master the basic knowledge, but also grasp the professional development direction in time In order to formulate learning goals more targeted, so as to be able to grow into high-quality medical talents that meet the national development requirements in the wave of industry development.

In addition, teachers also need to prevent students from using mechanical memory to learn knowledge, because this will not only affect students' learning initiative, but also make students' forgetting rate faster, thereby affecting their confidence in learning knowledge. Therefore, when teaching, teachers can introduce more medical examples that make students interested in learning, so that students can better understand what they have learned in order to improve their memory efficiency. This can not only help students improve the quality of learning, but also achieve the purpose of effectively promoting the smooth progress of medical education reform.

\section{Innovate teaching links to ensure teaching effectiveness}

In order to maintain the teaching progress, many teachers rarely give students enough time to think and discuss and study the knowledge content they need to master in order to maintain the teaching progress. Although such teaching methods can achieve the purpose of advancing the successful completion of teaching tasks to a certain extent, students have always been unable to ensure the improvement of learning efficiency in the process of exerting their own speculation.

Therefore, when conducting teaching activities, teachers should combine the actual cognition level of college students and innovate the teaching and teaching links, so that students can jointly learn knowledge through mutual cooperation and help. Through the introduction of cooperative learning, teachers divide class students into several groups according to the actual learning level, and according to the specific content of the lectures, arrange the discussion tasks for different groups in class, encouraging students to be able to diverge from each other's thinking ability To complete the learning of knowledge. After the student discussion is completed, the learning results need to be displayed in the form of an overall group report, which will be scored by the teacher and other group members. This can not only provide students with a better space for thinking, but also ensure a better rise in teaching effectiveness in the process of mobilizing their thinking consciousness.

\section{Conclusion}

The constant progress of the times requires higher development in the field of education, so in order to ensure the smooth development of medical education in colleges and universities, teachers should not blindly hinder the smooth progress of classroom teaching activities under the influence of old teaching concepts when conducting teaching work Instead, we should proceed from reality and find specific strategies to promote the smooth implementation of education reform. This will not only enable students to improve the quality of learning in a better learning environment, but also promote the vigorous development of my country's medical education while ensuring the effectiveness of classroom teaching.

\section{References}

1. Shi Y, Zhang HQ, Wang D, et al. Thinking on the national medical education examination for histology and embryology. Continuing Medical Education 2019; 33(12); 32-33.

2. $\mathrm{Xu} \mathrm{T}$, Li CB, Wang F, et al. Using educational informatization to promote the reform of college education and teaching_-Taking Inner Mongolia Medical University as an example. Medical Education Management 2018; 4(02): 81$84+94$.

3. Cheng CK, Sun LJ, Luo J, et al. New ideas for the reform of university journals_-Practice and reflections on the teaching of "medical paper writing" course for 21-year medical masters. Journal Editors 2016; (00): 25-28. 